\title{
Release Characteristics of Diltiazem Hydrochloride Wax-Matrix Granules - Thermal Sintering Effect
}

\author{
${ }^{* 1}$ UHUMWANGHO, M U; ${ }^{2}$ RAMANA MURTHY, K V
}

${ }^{1}$ Department of Pharmaceutics and Pharmaceutical Technology, Faculty of Pharmacy, University of Benin, PMB 1154, Benin, Nigeria

${ }^{2}$ University College of Pharmaceutical Sciences, Andhra University, Visakhapatnam -530003, India

\begin{abstract}
The aim of this study was to investigate the release characteristics of matrix (non-disintegrating) granules consisting of diltiazem hydrochloride (model drug) and glyceryl behenate (a wax matrix forming polymer) for sustained release application using sintering technique. The granules of diltiazem hydrochloride-wax matrix were prepared by melt granulation technique. This was formed by triturating the drug powder with a melted glyceryl behenate (drug: wax ratio, 3:1). The granules were subsequently sintered at 60 and $70^{\circ} \mathrm{C}$ for $1,1.5$ and $3 \mathrm{~h}$. The unsintered and sintered wax matrix granules of diltiazem hydrochloride were evaluated for physicochemical parameters and in vitro dissolution studies. The dissolution data were subjected to analysis using different mathematical models namely - zero order flux, first order, Higuchi square root of time, then Korsmeyer and Peppas model. Fourier-Transform Infrared Spectroscopy (FTIR) was carried out to investigate any chemical interactions between the drug and the added recipients before and after sintering. There was increased drug release retardation of diltiazem hydrochloride-wax matrix granules with sintering. The retardation depended on the temperature and duration of sintering. For instance, formulations sintered at 60 and $70^{\circ} \mathrm{C}$ for a period of $1.5 \mathrm{~h}$ gave maximum release $\left(\mathrm{m}_{\infty}\right)$, time to attain maximum release $\left(\mathrm{t}_{\infty}\right)$ and dissolution rate $\left(\mathrm{m}_{\infty} / \mathrm{t}_{\infty}\right)$ of $96.1 \%, 95.2 \%, 5 \mathrm{~h}, 9 \mathrm{~h}, 19.2 \% \mathrm{~h}^{-1}$ and $10.6 \% \mathrm{~h}^{-1}$ respectively. The drug release was by Higuchi controlled diffusion mechanism and it followed Fickain diffusion mechanism $(\mathrm{n}<0.45)$. Sintering technique enhanced the extent of drug retardation from the systems studied. There was no chemical interaction between the model drug and the added recipients as shown in the FTIR studies. @JASEM
\end{abstract}

\section{KEYWORDS: Thermal Sintering technique, sustained release, Fourier-Transform Infrared Spectroscopy}

Currently, significant attention is being focused on the development of sustained release dosage forms due to its numerous advantages over conventional dosage forms. Some of these advantages include: maintenance of a steady plasma level of the drug over a prolonged time period, reduction in adverse side effects, patient convenience and compliance e.t.c (Aulton, 2002). Sintering technique is defined as the bonding of adjacent particle surfaces in a mass of powder, or in a compact by the application of heat (Rakesh and Ashok, 2009). Thermal sintering involves the heating of a compact at a temperature below the melting point of the solid constituents in a controlled environment under atmospheric pressure. The changes in the hardness and disintegration time of tablets stored at elevated temperatures have been described as a result of thermal sintering effect (Satyabrata et al., 2010). Recently, Flowerlet et al., (2010) developed an oral sustained release dosage formulation of metformin hydrochloride matrix tablets by sintering the polymer matrix with organic vapour such as acetone. Thermal sintering process has been used for the fabrication of sustained release matrix dosage forms for the stabilization and retardation of drug release from different systems (Cohen et al., 1984). Previously, Rowe et al (1973), have reported that the process of thermal sintering affect the pore structure and strength of plastic matrix tablets.

Polymer films with different permeability have been explored to modify drug release from drug particles. Some examples mentioned in the literature include: films with the drug as a solution in a polymer matrixe.g. monolithic devices (Oppenheim 1981; Douglas et al., 1987; Davis and Illum, 1988) polymer coated reservoir devices (Lehmann, et al., 1979), polymeric colloidal particles (microparticles or nanoparticles) either in the form of reservoir or matrix devices (Oppenheim, 1981; Douglas et al., 1987;) and osmotically "controlled" devices (Zentner et al., 1985; Muhammad et al., 1991). These methods are however very complicated and expensive since it requires the use of organic solvents as coating fluid. Moreover, these organic solvents are hazardous to the environment. Waxes have been used either as matrix former or as a coating polymer to sustain the release of drugs (Zhou et al., 1996; Zhang et al., 2001; Uhumwangho and Okor, 2006). An alternative simple approach, which was considered in the present study, is melt granulation whereby the drug powder is triturated with a melted wax serving as a hydrophobic retard release agent. The resulting granules consist of the drug particles dispersed in a wax continuous matrix.

Diltiazem hydrochloride (DZH) is a nondihydropyridine member of the group of drugs known as benzothiazepines, which are a class of calcium channel blockers. It is used in the treatment of hypertension, angina pectoris, and some types of arrhythmia (Buckley et al, 1990). Its chemical formulaf is [(2S,3S)-5-(2-dimethylaminoethyl)-2-(4methoxyphenyl)-4-oxo-2,3-dihydro-1,5benzothiazepin-3-yl] acetate, with a molecular weight of 414.16 . Its bioavailability is about $30 \%$ to $40 \%$ due 
to first pass metabolism with a biological half-life of about 3.5 hours (Hermann et al., 1983; Smith et al., 1983). The aim of this study was to prepare waxmatrix granules by melt granulation technique using DZH as a model drug. These wax-matrix granules were later sintered thermally at different temperatures and time duration. Consequently, the effect of sintering temperature and duration on the drug release profiles and physicochemical parameters were investigated.

\section{MATERIALS AND METHODS}

Materials: The active ingredient used in the study was diltiazem hydrochloride (Cipla Ltd, Goa, India). The matrix former used was glyceryl behenate (Dr Rheddy's Laboratory, India), a fine white solid powder with melting point of $83^{\circ} \mathrm{C}$. Magnesium stearate (Qualikems Fine Chemical Pvt Ltd, India) was used as the lubricant. Other materials used were analytical grade.

Melt granulation technique: Glyceryl behenate (30 g) was melted in a stainless steel container in a water bath at a temperature higher than its melting point (i.e. $\left.83^{0} \mathrm{C}\right)$. A sample of DZH powder $(90 \mathrm{~g})$ was added to the melted wax and thoroughly mixed with a glass rod. It was then allowed to cool to room temperature $\left(35 \pm 2^{0} \mathrm{C}\right)$. The mass was pressed through a sieve of mesh 10 (aperture size; $710 \mu \mathrm{m}$ ) to produce wax-matrix granules.

Sintering of the matrix granules: The matrix granules were then subjected to thermal treatment by placing them on aluminum foil and subjecting to sintering at different temperatures (Kondaiah 2002; Luk and Jane, 1996) i.e. 60 and $70^{\circ} \mathrm{C}$ for different durations (1, 1.5 and $3 \mathrm{~h}$ ) in a hot air oven (Labhosp, Mumbia, India).

Packing property of the matrix granules: The packing properties were determined by measuring the difference between bulk density (BD) and the tapped density (TD) using standard procedure. In the procedure, $20 \mathrm{~g}$ of matrix granule sample was placed in a $250 \mathrm{ml}$ clean, dry measuring cylinder and the volume, $\mathrm{V}_{0}$ occupied by the sample without tapping was determined. An automated tap density tester (model C-TDA2, Campbell Electronics, Mumbai, India) was used for tapping the granules according to USP Chapter 616 Method I (Manish et al, 2001). After 100 taps the occupied volume, $\mathrm{V}_{100}$ was noted. The bulk and tap densities were calculated from these volumes $\left(\mathrm{V}_{0}\right.$ and $\left.\mathrm{V}_{100}\right)$ using the formula. Density = Weight/Volume occupied by sample. From the data, Hausner ratio and compressibility index were determined (US Pharmacopeia, 2006).

Flow property of matrix granules: The flowability of the granules was determined by measuring the angle of repose formed when a sample of the granules $(40 \mathrm{~g})$ was allowed to fall freely from the stem of a funnel to a horizontal bench surface. The radius (r) and the height $(\mathrm{H})$ of the powder heap were determined and then the angle of repose $(\theta)$ was calculated (Maheshwari et al., 2003).

Hardness-Friability Index (HFI): This was calculated on the basis of the results of the friability test. In the procedure, $20 \mathrm{~g}$ of matrix granules were placed in the drum of an Erweka friabulator (Heusenstamm, Germany) rotating at $20 \mathrm{rev}$ per min for $10 \mathrm{~min}$. The matrix granules were then screened through a 60\# sieve to remove the fines generated (Nasipuri and Omotosho, 1985; Eichie et al., 2005; Singh et al., 2007). Hence, the hardness-friability index was calculated using the equation below:

$\% \mathrm{HFI}=\mathrm{F}_{\mathrm{A}} / \mathrm{F}_{\mathrm{B}} \times 10$; where $\mathrm{F}_{\mathrm{A}}$ and $\mathrm{F}_{\mathrm{B}}$ are weights after and before friability determination respectively.

Encapsulation of the matrix granules: Samples of matrix granules before and after sintering (drug content, 90mg) were filled manually into plain hard gelatin capsules. The capsules were kept in airtight containers before their use in in-vitro dissolution studies.

In vitro dissolution test: One capsule filled with the matrix granules was placed in a cylindrical basket (aperture size $425 \mu \mathrm{m}$ : diameter 20mm; height $25 \mathrm{~mm}$ ), and immersed in $900 \mathrm{ml}$ of leaching fluid $\left(0.1 \mathrm{~N}\right.$ hydrochloric acid maintained at $\left.37 \pm 2^{\circ} \mathrm{C}\right)$. The fluid was stirred at 100rpm (Model Disso 2000, Lab India). Samples of the leaching fluid $(5 \mathrm{ml})$ were withdrawn at selected time intervals with a syringe fitted with a cotton wool plug and replaced with an equal volume of drug-free dissolution fluid. The samples were suitably diluted with blank dissolution fluid and were analysed for content of diltiazem at $\lambda_{\max }, 236 \mathrm{~nm}$ by using an Elico SL 210 UV-Visible double beam spectrophotometer (Elico, India). The samples were filtered with Whatman No. 3 filter paper before assay and the amounts released were expressed as a percentage of the drug content in each dissolution medium. The dissolution test was carried out in quadruplicate and the mean results reported. Individual results were reproducible to $\pm 10 \%$ of the mean.

Determination of rate order kinetics and mechanism: The dissolution data were analyzed on the basis of zero order, (cumulative amount of drug released vs. time), first order rate (log cumulative amount of drug remaining vs. time), Higuchi model (cumulative amount of drug released vs. square root of time) and Korsmeyer and Peppas (log cumulative amount released vs log time). These are the most frequently reported kinetics of drug release from drug particles 
and their solid dosage forms (Higuchi, 1963; Korsmeyer et al., 1983; Peppas, 1985; Harland et al., 1988).

The kinetic models order equations are:

Zero order: $\mathrm{m}=\mathrm{k}_{0} \mathrm{t}$

First order: $\log \mathrm{m}_{1}=\log \mathrm{m}_{0}-0.43 \mathrm{k}_{1} \mathrm{t}$

$\mathrm{M}=\mathrm{k}_{\mathrm{H}} \mathrm{t}^{1 / 2}$

Korsmeyer and Peppas dissolution model $=\log \mathrm{m}$ $=\log \mathrm{k}_{2}+\mathrm{nlogt}$; where $\mathrm{m}$ is the percentage (\%) amount of drug released in time $\mathrm{t} ; \mathrm{m}_{1}$ is the residual amount $(\%)$ of drug in time $\mathrm{t} ; \mathrm{m}_{0}$ is the initial amount of drug $(100 \%)$ at the beginning of the first order release; $\mathrm{k}_{0}, \mathrm{k}_{1}, \mathrm{k}_{\mathrm{H}}$ and $\mathrm{k}_{2}$ are the release rate constants for the zero, first order, the Higuchi models and Korsmeyer and Peppas dissolution models respectively. The $\mathrm{n}$ is the diffusion release exponent that could be used to characterize the different release mechanism. Value of $\mathrm{n}$ below 0.45 indicates Fickian diffusion mechanism and $\mathrm{n}$ value between 0.45 and 0.89 indicates anomalous transport, often termed as first-order release. If the $\mathrm{n}$ value reaches 0.89 or above, the release can be characterized by case II and super case II transport, which means the drug release rate does not change over time and the drug is released by zero-order mechanism. The correlation coefficient (r) for each rate order was also calculated.

Fourier Transform Infra Red (FTIR): The FTIR spectrum of the different samples were recorded in an Infra Red spectrometer (Nicolet Magna 4R 560, MN, USA) using potassium bromide discs prepared from powdered samples. Infrared spectrum was recorded in the region of 4000 to $400 \mathrm{~cm}^{-1}$.

Statistical analysis: All data obtained were subjected to student $\mathrm{t}$ - test $(\mathrm{p}<0.05)$ to test for significance of difference.

\section{RESULTS AND DISCUSSION}

Effect of sintering on physicochemical parameters of unsintered and sintered wax-matrix granules: The effects of sintering on the physicochemical parameters of unsintered and sintered matrix granules are presented in table 1 . It was observed that all the matrix granules were free flowing with angle of repose $\leq 29^{\circ}$ and Carr's index $\leq 19.3 \%$. (Gordon et al., 1990). There was a slight decrease in these values i.e. angle of repose and Carr's index (See table 1) as temperature and duration of sintering increased, although, the difference did not vary significantly $(p>0.05)$. On the other hand, it was observed that all the sintered matrix granules had high HFI value when compared with the unsintered matrix granules (See table 1). However, the differences varied significantly $(p<0.05)$. More so, with increase in temperature and duration of sintering, the HFI values increased correspondingly (See Table 1). The increase in hardness with increase in temperature and duration of sintering might be attributable to the fusion of the wax matrix particles or the formation of welded bonds among the matrix particles after cooling. Previously, some researchers reported that asperity melting and formation of welded bonds resulted in high tensile strength of tablets, this occurs with compression at high temperature (Pilpel and Esezobo, 1977; Kurup and Pilpel, 1979; Esezobo and Pilpel, 1986).

Dissolution profiles of matrix granules: The dissolution profiles of the unsintered and sintered matrix granules at 60 and $70^{\circ} \mathrm{C}$ at different time durations are presented in Fig 1. It was observed that the unsintered matrix granules were able to retard the drug for $2 \mathrm{~h}$. Generally, as the temperature and duration of sintering of the matrix granules increased, the time to attain maximum release $\left(\mathrm{t}_{\infty}\right)$ increased correspondingly.

For instance, when matrix granules was sintered at $60^{\circ} \mathrm{C}$ for 1.5 and $3 \mathrm{~h}$ (i.e. formulations $\mathrm{GB}_{3}$ and $\mathrm{GB}_{4}$ ) the maximum release $\left(\mathrm{m}_{\infty}\right)$ and time to attain maximum release $\left(\mathrm{t}_{\infty}\right)$ were $96.1 \%, 94.2 \%, 5 \mathrm{~h}$ and $6 \mathrm{~h}$ respectively, while their corresponding values at $70^{\circ} \mathrm{C}$ for time duration of 1.5 and $3 \mathrm{~h}$ (i.e. formulations $\mathrm{GB}_{6}$ and $\mathrm{GB}_{7}$ ) were $95.2 \%, 96.2 \%$, 9h and $12 \mathrm{~h}$ (See table 2). Hence, sintering temperature and duration markedly affected the drug release properties of the wax-matrices granules

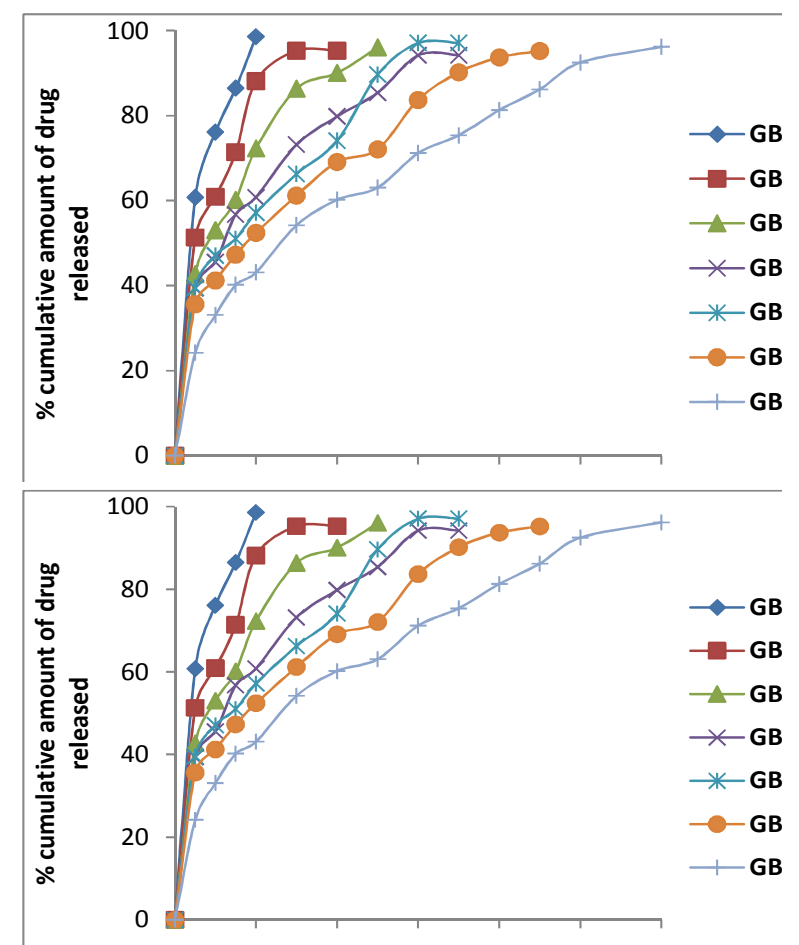

Fig 1: Release profiles of $\mathrm{DZH}, \mathrm{CB}_{1}$ is unsintered matrix granules and $\mathrm{CB}_{2}, \mathrm{CB}_{3}, \mathrm{CB}_{4}$, are sintered matrix granules at $60^{\circ} \mathrm{C}$ for $1 \mathrm{~h}$, $1.5 \mathrm{~h}$ and $3 \mathrm{~h}$ respectively while $\mathrm{CB}_{5}, \mathrm{CB}_{6}, \mathrm{CB}_{7}$ are sintered matrix granules at $70^{\circ} \mathrm{C}$ for $1,1.5$ and $3 \mathrm{~h}$ respectively. 
The dissolution rate $\left(\mathrm{m}_{\infty} / \mathrm{t}_{\infty}\right)$ also decreased as the sintering temperature and duration of sintering increased (Table 2). This finding is in conformity with previous literature (Rao et al., 2001; Rao et al., 2003). The retardation in drug release on sintering may be due to softening of the wax particles during sintering and hence penetrated the empty spaces, forming a continuous layer around the drug particles in the matrix granules (Singh et al., 2007). This resulted in a decrease of the drug particles surface to the dissolution medium-resulting in drug retardation from the matrix granules. It may also be attributed to the increase in HFI (See Table 1) which might decrease porosity and hence a reduction in influx of the dissolution medium into the drug particles in the matrix granules. However, formulation $\mathrm{GB}_{7}$ which was sintered at $70^{\circ} \mathrm{C}$ for $3 \mathrm{~h}$ duration was able to retard the drug for a period of $12 \mathrm{~h}$.

Table 1: Physicochemical parameters of unsintered and sintered wax-matrix granules at different temperatures $\left(60^{\circ} \mathrm{C}\right.$ and $\left.70^{\circ} \mathrm{C}\right)$ and time durations (1,1.5 and 3h). Note: $C B_{1}$ is unsintered matrix-granules, $C B_{2}, C B_{3}, C B_{4}$ are sintered matrix granules at $60^{\circ} C$ for $1,1.5$ and $3 h$ respectively while $C B_{5}, C B_{6}$ and $C B_{7}$ are sintered matrix granule at $70^{\circ} C$ for $1,1.5$ and 3 h respectively. HFI $=H a r d n e s s$ friability index

\begin{tabular}{|c|c|c|c|c|c|c|c|}
\hline Parameters evaluated & Unsintered & \multicolumn{3}{|c|}{ Sintered at $60^{\circ} \mathrm{C}$} & \multicolumn{3}{c|}{ Sintered at $70^{0} \mathrm{C}$} \\
\hline & $\mathrm{CB}_{1}$ & $\mathrm{CB}_{2}$ & $\mathrm{CB}_{3}$ & $\mathrm{CB}_{4}$ & $\mathrm{CB}_{5}$ & $\mathrm{CB}_{6}$ & $\mathrm{CB}_{7}$ \\
\hline Bulk density $\left(\mathrm{g} / \mathrm{cm}^{3}\right)$ & $0.67 \pm 0.04$ & $0.64 \pm 0.03$ & $0.60 \pm 0.01$ & $0.57 \pm 0.02$ & $0.66 \pm 0.03$ & $0.65 \pm 0.04$ & $0.61 \pm 0.02$ \\
\hline Tap density $\left(\mathrm{g} / \mathrm{cm}^{3}\right)$ & $0.83 \pm 0.03$ & $0.79 \pm 0.04$ & $0.73 \pm 0.02$ & $0.69 \pm 0.03$ & $0.80 \pm 0.02$ & $0.78 \pm 0.04$ & $0.72 \pm 0.03$ \\
\hline Carr's index $(\%)$ & $19.3 \pm 1.1$ & $18.9 \pm 1.3$ & $17.8 \pm 1.1$ & $17.4 \pm 1.2$ & $17.5 \pm 1.4$ & $16.7 \pm 1.2$ & $15.3 \pm 1.3$ \\
\hline Angle of repose $\left(0^{0}\right)$ & $28.6 \pm 1.3$ & $27.1 \pm 1.6$ & $28.4 \pm 1.5$ & $26.5 \pm 1.2$ & $26.3 \pm 2.1$ & $25.9 \pm 1.3$ & $25.5 \pm 1.4$ \\
\hline Hausner ratio & 1.23 & 1.23 & 1.22 & 1.21 & 1.21 & 1.20 & 1.18 \\
\hline HFI & 51 & 69 & 72 & 81 & 75 & 89 & 95 \\
\hline
\end{tabular}

Table 2: Dissolution parameters $\left\{\mathrm{m}_{\infty}(\%), \mathrm{t}_{\infty}(\mathrm{h}), \mathrm{m}_{\infty} / \mathrm{t}_{\infty}\left(\% \mathrm{~h}^{-1}\right)\right\}$ of the different matrix granules formulations.

\begin{tabular}{|c|c|c|c|c|c|c|c|}
\hline Formulations & $\mathrm{GB}_{1}$ & $\mathrm{~GB}_{2}$ & $\mathrm{~GB}_{3}$ & $\mathrm{~GB}_{4}$ & $\mathrm{~GB}_{5}$ & $\mathrm{~GB}_{6}$ & $\mathrm{~GB}_{7}$ \\
\hline $\mathrm{m}_{\infty}(\%)$ & 98.6 & 95.3 & 96.1 & 94.2 & 97.1 & 95.2 & 96.2 \\
\hline $\mathrm{t}_{\infty}(\mathrm{h})$ & 2 & 3 & 5 & 6 & 6 & 9 & 12 \\
\hline $\mathrm{m}_{\infty} / \mathrm{t}_{\infty}\left(\% \mathrm{~h}^{-1}\right)$ & 49.3 & 31.8 & 19.2 & 15.7 & 16.2 & 10.6 & 8.02 \\
\hline
\end{tabular}

Table 3: Correlation coefficient (r-values) and release kinetics of DZH $(n=3)$ from different matrix granules formulations when the data were analysed according to the zero order, first order, Higuchi, and Korsmeyer and Peppas models.

\begin{tabular}{|c|c|c|c|c|c|c|c|c|}
\hline Models & \multicolumn{2}{|c|}{ Zero } & \multicolumn{2}{c|}{ First } & \multicolumn{2}{c|}{ Higuchi } & \multicolumn{2}{c|}{ Korsmeyer and Peppas } \\
\hline Formulations & $\mathrm{r}$ & $\mathrm{k}_{0}$ & $\mathrm{r}$ & $\mathrm{k}_{1}$ & $\mathrm{r}$ & $\mathrm{k}_{\mathrm{H}}$ & $\mathrm{r}$ & $\mathrm{n}$ \\
\hline $\mathrm{GB}_{1}$ & 0.8341 & 44.6 & 0.8592 & 0.39 & 0.9968 & 52.6 & 0.9953 & 0.34 \\
\hline $\mathrm{GB}_{2}$ & 0.7327 & 20.5 & 0.9178 & 0.14 & 0.9189 & 37.8 & 0.9508 & 0.33 \\
\hline $\mathrm{GB}_{3}$ & 0.8013 & 16.1 & 0.9837 & 0.11 & 0.9771 & 36.6 & 0.9855 & 0.37 \\
\hline $\mathrm{GB}_{4}$ & 0.8153 & 10.9 & 0.9698 & 0.07 & 0.9884 & 30.1 & 0.9903 & 0.35 \\
\hline $\mathrm{GB}_{5}$ & 0.8636 & 11.6 & 0.9139 & 0.10 & 0.978 & 32.3 & 0.9673 & 0.36 \\
\hline $\mathrm{GB}_{6}$ & 0.8701 & 8.6 & 0.9638 & 0.06 & 0.9918 & 27.7 & 0.9843 & 0.36 \\
\hline $\mathrm{GB}_{7}$ & 0.9023 & 6.9 & 0.9463 & 0.04 & 0.9962 & 26.4 & 0.9973 & 0.43 \\
\hline
\end{tabular}

Drug release mechanism: A good knowledge of the drug release kinetics will provide a proper understanding of the drug release mechanism. Four mathematical models were used for analysis: zeroorder kinetics, first-order kinetics, Higuchi mechanism, and Korsmeyer and peppas model (Higuchi, 1963; Korsmeyer et al., 1983; Peppas, 1985; Harland et al., 1988). The values of the correlation coefficients (r) and the release rate constants are presented in table 3 . The r-values for all the formulations were zero order $(0.7327$ to 0.9023$)$, first order (0.8592 to 0.9837), Higuchi (0.9189 to 0.9968 ) and Korsmeyer and Peppas model (0.9508 to 0.9973). Drug release from these systems is studied by Higuchi diffusion controlled mechanism. The release exponents (n) value for the Korsmeyer and Peppas model will enable us understand the drug release mechanism. It was observed that $n$ values were $<0.45$ for all the formulations studied (See Table 3 ). This indicates that the release of diltiazem hydrochloride from these systems followed Fickian diffusion mechanism (Korsmeyer et al., 1983).

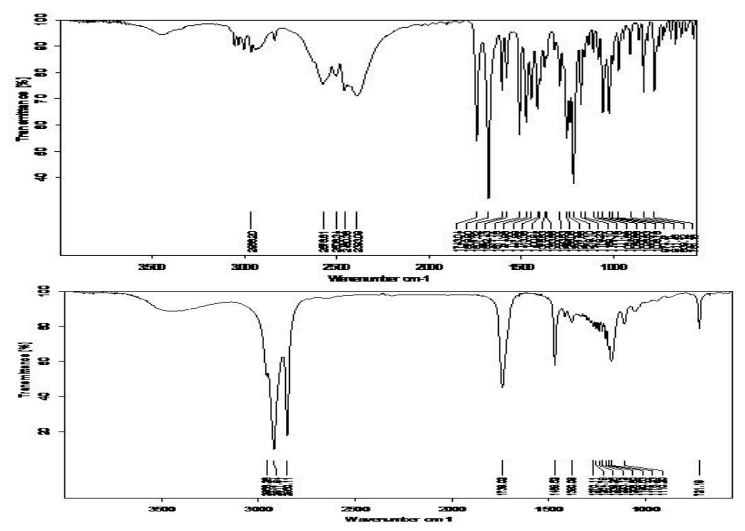


Release Characteristics of Diltiazem.....

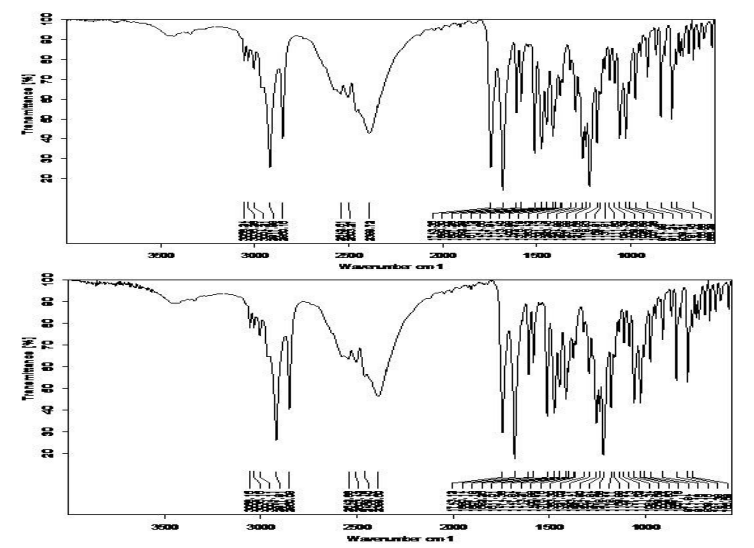

Fig 2: FTIR of (a) DHZ, (b) glyceryl behenate (c) unsintered DHZ prepared with glyceryl behenate and (d) sintered DHZ prepared with glyceryl behenate .

FTIR: Formulation $\mathrm{GB}_{7}$ was considered for FTIR studies since it was able to retard the drug for a period of $12 \mathrm{~h}$. This study was carried out in order to investigate if there was any chemical interaction between added excipients and DZH in the formulation $\left(\mathrm{GB}_{7}\right)$ before and after sintering. The FTIR of the pure drug, glyceryl behenate, unsintered and sintered matrix granules were recorded (See Fig $2 \mathrm{a}, \mathrm{b}, \mathrm{c}$ and $\mathrm{d}$ respectively). The IR spectrum of DZH showed characteristic peaks at $1743.04 \mathrm{~cm}^{-1}$ (ester$\mathrm{C}=\mathrm{O}$ ) and $1679.0 \mathrm{~cm}^{-1}$ (amide- $\mathrm{C}=\mathrm{O}$ ). However, for the glyceryl behenate alone (without drug or other excipients), IR spectrum showed signals at $2956 \mathrm{~cm}^{-1}$ (for aliphatic, C-H stretch), and $1739.02 \mathrm{~cm}^{-1}$ (for ester, $\mathrm{C}=\mathrm{O}$ stretch). These spectra were compared with the IR spectrum of the unsintered and the sintered wax-matrix granules $\left(\mathrm{GB}_{7}\right)$. It was observed that the IR spectra showed both the principal peaks of DZH $\left(1743\right.$ and $\left.1649 \mathrm{~cm}^{-1}\right)$ and glyceryl behenate $\left(1739 \mathrm{~cm}^{-1}\right.$ for ester), suggesting that there was no chemical interaction between the DZH and added excipients (such as glyceryl behenate) in both sintered and unsintering matrix granules.

Conclusion: Sintering technique enhanced the extent of drug retardation from the systems studied. Formulation $\mathrm{GB}_{7}$ sintered at $70^{\circ} \mathrm{C}$ for $3 \mathrm{~h}$ was able to sustain the drug for a period of $12 \mathrm{~h}$ with a maximum release of $96.2 \%$. The FTIR studies showed that the model drug was not affected by the temperature and time duration used for sintering.

Acknowledgment: The author wish to thank Centre for Cooperation in Science and Technology among Developing Societies (CCSTDS) for providing the grant used in this research.

\section{REFERENCES}

Aulton, M. E. (2002). Pharmaceutics: The Science of Dosage Form Design. $2^{\text {nd }}$ Ed., Churchill Livingstone, Spain, pp. 289-305.
Buckley, M.T. Grant, S.M. Goa, K .L. McTavish, D. and Sorkin, E.M. (1990). Diltiazem. A reappraisal of its pharmacological properties and therapeutic use. Drugs. 39, 757-806.

Cohen, J., Siegel, R.A. and Langer, R. (1984). Sintering technique for the preparation of polymer matrices for the controlled release of Macromolecules. J Pharm Sci. 73, 1034-1037.

Davis, S. S.; and Illum, L. (1988). Polymeric Microspheres as Drug Carriers. Biomaterials. 9, 111115.

Douglas, S.J.; Davis, S.S.; and Illum, L. (1987). Nanoparticles in Drug Delivery. CRC Critical Review Ther. Drug Carr. Syst. 3 (3), 233-261.

Eichie, F.E., Okor, R.S., Uhumwangho, M.U. and Osakue, I.Y. (2005). Relationship between slugging pressure and brittle fracture tendency of resulting tablets - a case study for aspirin tablets. Trop. J. Pharm. Res. 4, 483-487

Esezobo, S. and Pilpel, N. (1986). The effect of temperature on the plastoelasticity of some pharmaceutical powders and on the tensile strengths of their tablets. J. Pharm. Pharmacol. 38, 409-413.

Flowerlet, M, Anoop, K.R, Shoma, J and Asha, J. (2010). Formulation of metformin hydrochloride matrix tablets by sintering technique and its evaluation 2, 293306.

Gordon, R.E., Rosanske, W.T., Fonner, D.E., Anderson, N. R. and Banker, G.S. (1990); Granulation technology and tablet characterization. In: Lieberman HA, Lachman L, Schwartz JB, eds. Pharmaceutical Dosage Forms: Tablets. New York, NY: Marcel Dekker; pp 245-348.

Harland, R.S., Gazzaniga, A., Sangalli, M.E., Colombo, P. and Peppas, N.A. (1988). Drug/polymer matrix: swelling and dissolution. Pharm Res. 5, 488-494.

Hermann, P., Rodger, S.D., Remones, G., Thenot, J.P., London, D.R. and Morselli, P.L. (1983). Pharmacokinetics of diltiazem after intravenous and oral administration. Eur J Clin Pharmacol. 24, 349-352.

Higuchi, T. (1963). Mechanism of sustained action medication. Theoretical analysis of rate release of solid drugs dispersed in solid matrices. J. Pharm. Sci. 52, 1145-1149.

Kondaiah, A. (2002). Design of controlled release nonerodible polymeric matrix tablets of theophylline using sintering technique. Indian J Pharm Sci. 64, 239-243

Korsmeyer, R., Gurny, R. and Peppas, N. (1983). Mechanisms of solute release from porous hydrophilic polymers. Int J Pharm. 15, 25-35.

Kurup, T. R. R. and Pilpel, N. (1979). The effect of binding agents on the tensile strengths of powders and tablets. Asian J. Pharm. Sci. 1, 75 - 90. 
Lehmann, K.O.R., Bossler, H.M. and Dreher, D.K. (1979). Controlled Drug Release From Small Particles Encapsulated with Acrylic Resin. Niol Macromol. Monogr. Polym. Delivery Systs. 5, 111-119.

Luk, C.L. and Jane, H.L. (1996). Sintering in pharmaceutics. In: Swarbrick J, Boylan JC, (Eds.) Encyclopedia of Pharmaceutical Technology. Vol.14. New York, NY: Marcel Dekker; 87-101.

Maheshwari, M., Ketkar, A.R., Chauhan, B., Patil, V.B. and Paradkar, A.R. (2003). Preparation and characterization of ibuprofen-cetyl alcohol beads by melt solidification technique: Effect of variables. Int $\mathbf{J}$ Pharm., 261, 57-67.

Manish, K.G., Goldman, D., Robin, H. B., and YinChao, T. (2001). Enhanced drug dissolution and bulk properties of solid dispersions granulated with a surface adsorbent. Pharm. Dev.Tech., 6(4), 563-572.

Muhammad, N.A., Boisvert, W., Harris, M.R., and Weiss, J. (1991). Modifying the Release Properties of Eudragit L30D. Drug Dev. and Ind. Pharm. 17, 24972509.

Nasipuri, R.N. and Omotosho, J.A. (1985). Influence of surfactant-treated starch on the disintegration and dissolution of sulphadiazine tablets. J Pharm Pharmacol. 37, 212-213.

Oppenheim, R.C.; (1981); Solid Colloidal Drug Delivery Systems: Nanoparticles. Int. J. Pharm. 8, 217234.

Peppas, N.A. (1985). Analysis of Fickian and nonFickian drug release from polymers. Pharm Acta Helv. $60,110-111$

Pilpel, N. and Esezobo, S. (1977). The effect of temperature on the tensile strength and disintegration of paracetamol and oxytetracycline tablets. J. Pharm. Pharmacol. 29 (7), 389-392.

Rakesh, P. and Ashok, B. (2009). Formulation development and process optimization of theophylline sustained release matrix tablet. Int J Pharm and Pharm Sci. 2, 30-42.
Rao, S.B., Seshasayana, A., Himasankar, K., Raju, Y.P. and Murthy, K.V.R. (2003). Design and evaluation of ethylene vinyl acetate sintered matrix tablets. Indian J Pharm Sci. 65, 496-502.

Rao, S.B., Seshasayana, A., Narayan, C.P.S., Sudha, K.S., Pardhasaradhi, S.V., Kumar, N.R. and Muthy, K.V.R. (2001). Studies on release of rifampicin from sintered matrix tablets. Indian J Pharm Sci. 63, 371-378.

Rowe, R. C., Elworthy, P. H. and Ganderton, D. (1973). The effect of sintering on the pore structure and strength of plastic matrix tablets. J Pharm Pharmacol. 25, Suppl:12P-16P.

Satyabrata, B., Ellaiah, P., Mohanty, C., Murthy, K.V.R., Bibhutibhusan, P. and Kumar, P. S. (2010); Design and in vitro Evaluation of Mucoadhesive Buccal Tablets of Perindopril Prepared by Sintering Technique. International J PharmTech Res 2, 1810-1823.

Singh, R., Poddar, S. S. and Chiva, A. (2007) Sintering of Wax for Controlling Release From Pellets. AAPS PharmSciTech. 8 (3), 1 -9.

Smith, M.S., Verghese, C.P., Shand, D.G. and Pritchett, E.L.C. (1983). Pharmacokinetic and pharmacodynamic effects of diltiazem. Am J Cardiol. 5, 11369-1374.

Uhumwangho, M. U. and Okor, R. S. (2006). Effect of matrix granulation and wax coating on the dissolution rates of paracetamol granules. Afr. J Bio. 5 (9), . 766769 .

US Pharmacopeia. USP Chapter <616> Bulk Density and Tapped Density. Rockville, MD: USP; 2006, 2638.

Zentner, G.M., Rork, G.S. and Himmelstein, K.J. (1985). Osmotic Flow Through ontrolled Porosity Films: An Approach to Delivery of Water Soluble Compounds. J. Control. Rel. 2, 217-229.

Zhang, Y. E., Tchao, R. and Schwartz, J. B. (2001). Effect of processing methods and heat treatment on the formation of wax matrix tablets for sustained drug release. Pharm. Dev.Technol. 6, 131-144.

Zhou, F., Vervaet, C. and Remon, J. P. (1996). Matrix pellets based on the combination of waxes, starches and maltodextrins. Int J Pharm. 133, 155-160. 